\title{
Critical surface albedo and its implications to aerosol remote sensing
}

\author{
F. C. Seidel ${ }^{1, *}$ and C. Popp ${ }^{2}$ \\ ${ }^{1}$ Jet Propulsion Laboratory, California Institute of Technology, Pasadena, CA, USA \\ ${ }^{2}$ Empa, Swiss Federal Laboratories for Materials Science and Technology, Dübendorf, Switzerland \\ *Invited contribution by F. C. Seidel, recipient of the EGU Outstanding Student Poster Award 2011.
}

Correspondence to: F. C. Seidel (felix.seidel@jpl.nasa.gov)

Received: 30 September 2011 - Published in Atmos. Meas. Tech. Discuss.: 20 December 2011

Revised: 9 June 2012 - Accepted: 15 June 2012 - Published: 17 July 2012

\begin{abstract}
We analyse the critical surface albedo (CSA) and its implications to aerosol remote sensing. CSA is defined as the surface albedo where the reflectance at top-ofatmosphere (TOA) does not depend on aerosol optical depth (AOD). AOD retrievals are therefore inaccurate at the CSA. The CSA is obtained by derivatives of the TOA reflectance with respect to AOD using a radiative transfer code. We present the CSA and the effect of surface albedo uncertainties on AOD retrieval and atmospheric correction as a function of aerosol single-scattering albedo, illumination and observation geometry, wavelength and AOD. In general, increasing aerosol absorption and increasing scattering angles lead to lower CSA. In contrast to the strict definition of the CSA, we show that the CSA can also slightly depend on AOD and therefore rather represent a small range of surface albedo values. This was often neglected in previous studies. The following implications to aerosol remote sensing applications were found: (i) surface albedo uncertainties result in large AOD retrieval errors, particularly close to the CSA; (ii) AOD retrievals of weakly or non-absorbing aerosols require dark surfaces, while strongly absorbing aerosols can be retrieved more accurately over bright surfaces; (iii) the CSA may help to estimate aerosol absorption; and (iv) the presented sensitivity of the reflectance at TOA to AOD provides error estimations to optimise AOD retrieval algorithms.
\end{abstract}

\section{Introduction}

Atmospheric aerosols can affect human health (e.g. Brunekreef and Holgate, 2002), and they have a significant influence on the Earth's radiation budget by scattering and absorbing electromagnetic radiation (direct effect) or by cloud formation in their role as cloud condensation nuclei (indirect effect) (e.g. Ramanathan et al., 2001; Lohmann and Feichter, 2005; IPCC, 2007). Remote sensing from space has made important contributions to our knowledge on the spatio-temporal distribution and optical properties of aerosols. Aerosol remote sensing has helped to reduce large uncertainties regarding their impact on climate (IPCC, 2007). Many spaceborne sensors allow the retrieval of total vertical columnar aerosol scattering and absorption (extinction), known as aerosol optical depth (AOD). However, the retrieval of AOD is a challenging task and requires accurate prior knowledge of aerosol micro-physical and optical properties, such as size distribution, single-scattering albedo (SSA) and phase function. Further, it requires information on the directional surface reflectance and the state of the atmosphere (e.g. ozone and water vapour concentrations). AOD retrieval algorithms require a correct discrimination of the measured upwelling radiance into a part originating from molecule and aerosol scattering and a part caused by reflection from the Earth's surface.

Numerous studies demonstrated that the estimations of the surface albedo and related uncertainties are a major source of errors in AOD retrievals (e.g. Teillet et al., 1994; Kaufman et al., 1997; Popp et al., 2007; Kokhanovsky and Leeuw, 2009; Seidel et al., 2011). It was also shown that a certain range of surface albedo values provides difficulties for AOD retrievals where changes in aerosol scattering cancel out changes in aerosol absorption. The measured radiance at topof-atmosphere (TOA) becomes therefore insensitive to AOD changes. Fraser and Kaufman (1985) analysed and defined this surface albedo with regard to aerosol remote sensing applications as the critical surface reflectance. In this study, we will use the term critical surface albedo (CSA) to avoid 
possible confusions with reflectance functions (Eqs. 1, 2, and $6)$. Note that the CSA could represent either albedo or any reflectance factor, according to the use of term $a$ in Eq. (6). A few studies have taken advantage of the CSA to gain information about aerosol absorption from remote sensing measurements, which requires a good estimate as well as some albedo variability of the underlying surface in multiple pixels (Kaufman, 1987). For example, de Almeida Castanho et al. (2008) improved MODIS AOD retrievals over Sao Paulo, Brazil by estimating SSA prior to the AOD inversion using the CSA. Recently, Zhu et al. (2011) derived the absorption of biomass burning aerosols and Wells et al. (2012) estimated the SSA of dust over North Africa from MODIS applying the CSA method. The CSA is also of indirect relevance for the Earth's radiation budget at TOA, because it defines the surface albedo where a change in AOD has almost no influence on the TOA reflectance and the aerosol forcing changes sign. For example, increasing AOD over bright surfaces is usually darkening and increasing AOD over dark surfaces is brightening the Earth from space. The darkening leads to a positive aerosol forcing and warming, while the brightening leads to a negative aerosol forcing and hence cooling (Seinfeld and Pandis, 1998; Kaufman et al., 2002; Satheesh, 2002).

The objective of this study is to describe and analyse the CSA and the related AOD retrieval sensitivity as a function of aerosol properties under several observational conditions. Furthermore, our study aims at contributing to a better understanding of AOD retrieval sensitivities to surface albedo and related uncertainties. We base our theoretical study on the Lambertian surface approximation in order to avoid inherent assumptions on specific surface types with related bidirectional reflectance distribution function (BRDF) models. Nevertheless, the presented results are directly applicable to realistic surfaces as long as the corresponding surface reflectance factor (e.g. hemispherical-directional reflectance factor) is known for the solar and observational geometry.

\section{Method and data}

\subsection{Radiative transfer calculation}

Remote sensing data are complex in nature and influenced by many and often unknown parameters. We base our analysis of the CSA therefore on radiative transfer (RT) calculations to simulate different atmospheric and surface conditions for various satellite observation geometries. The RT equation can be solved approximately by e.g. the method of successive orders of scattering. We use here a vector version of the Second Simulation of a Satellite Signal in the Solar Spectrum (6S) RT model (Vermote et al., 1997; Kotchenova et al., 2006, 2008).

The RT model calculates the atmospheric coupled molecular-aerosol (ATM) and surface (SFC) contribution to the total spectral reflectance at TOA and wavelength $\lambda$ :

$R_{\lambda}^{\mathrm{TOA}}=R_{\lambda}^{\mathrm{ATM}}+R_{\lambda}^{\mathrm{SFC}}$.

The atmospheric intrinsic reflectance is given by the sum of single- and multiple-scattering (MS):

$R_{\lambda}^{\mathrm{ATM}}=\frac{\omega_{\lambda} P_{\lambda}(\Theta)}{4\left(\mu_{0}+\mu\right)}\left(1-e^{-\tau_{\lambda}\left[\frac{1}{\mu_{0}}+\frac{1}{\mu}\right]}\right)+R_{\lambda}^{\mathrm{MS}}$,

where

$\omega_{\lambda}=\frac{\sigma_{\lambda}^{\text {sca }}}{\sigma_{\lambda}^{\text {ext }}}$

is the SSA with the scattering $\left(\sigma_{\lambda}^{\text {sca }}\right)$ and extinction $\left(\sigma_{\lambda}^{\text {ext }}\right)$ efficiency, $\tau_{\lambda}$ is the total optical depth composed of AOD $\left(\tau_{\lambda}^{\text {aer }}\right)$ and Rayleigh optical depth $\left(\tau_{\lambda}^{\text {ray }}\right)$.

$P_{\lambda}(\Theta)=\frac{P_{\lambda}^{\text {aer }}(\Theta) \tau_{\lambda}^{\text {aer }}+P_{\lambda}^{\text {ray }}(\Theta) \tau_{\lambda}^{\text {ray }}}{\tau_{\lambda}}$

is the scattering phase function (cf. Fig. 1b) for solar radiation as function of forward (+) or backward (-) scattering angle:

$\Theta=\arccos \left[ \pm \mu_{0} \mu+\cos \left(\phi_{0}-\phi\right) \sqrt{\left(1-\mu_{0}^{2}\right)\left(1-\mu^{2}\right)}\right]$,

with $\mu_{0}=\cos \theta_{0}$ and $\mu=\cos \theta$, where $\theta$ is the viewing (VZA) and $\theta_{0}$ the solar zenith angle (SZA), and with the solar and viewing azimuth angle (VAA) $\phi_{0}$ and $\phi$, respectively. We assume isotropically reflected light from a homogeneous surface according to Lambert's law (Ångström, 1925; Chandrasekhar, 1960; Sobolev, 1972):

$R_{\lambda}^{\mathrm{SFC}}=\frac{a_{\lambda}}{1-a_{\lambda} s_{\lambda}} T_{\lambda}$,

where $T_{\lambda}=T_{\lambda}^{\downarrow} T_{\lambda}^{\uparrow}$ is the total down- and upwelling transmittance with $T_{\lambda}^{\downarrow}=e^{-\frac{\tau_{\lambda}}{\mu_{0}}}+t_{\lambda}^{\mathrm{dfs} \downarrow}$ and $T_{\lambda}^{\uparrow}=e^{-\frac{\tau_{\lambda}}{\mu}}+t_{\lambda}^{\mathrm{dfs} \uparrow}$, where $t_{\lambda}^{\mathrm{dfs}}$ denotes the diffuse transmittance (Note: we neglect gaseous absorptions for this study) and where $a_{\lambda}$ is the surface albedo and $s_{\lambda}$ is the spherical albedo to account for multiple surface and atmosphere scattering interactions.

\subsection{Synthetic data}

A synthetic dataset of TOA reflectances was computed with various single-scattering albedo, illumination and observation geometries, wavelengths and AOD values. An overview of the different parameters and their discretisation is given in Table 1 . Besides geometrical parameters $\left(\phi, \theta, \phi_{0}, \theta_{0}\right)$, surface albedo values from zero to unity are integrated to represent all possible surface types and clouds. In addition, simulations are performed at the wavelength $412 \mathrm{~nm}, 550 \mathrm{~nm}$, and $865 \mathrm{~nm}$ to investigate the spectral dependence of the CSA. The AOD ranges from zero to unity which is representative 


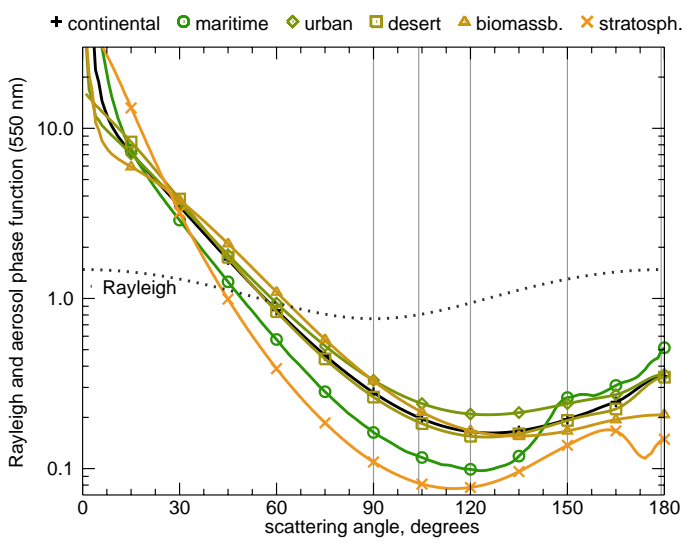

(a) Separated Rayleigh and aerosol phase functions.

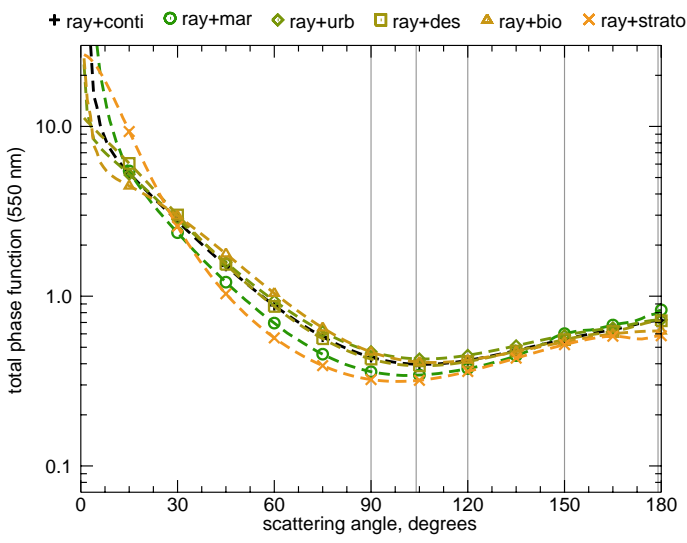

(b) Total phase functions.

Fig. 1. Rayleigh, aerosol and total phase functions $P_{550} \mathrm{~nm}$ as function of scattering angle $\Theta$ according to Eqs. (4) and (5) at 550 nm, with $\tau_{550 \mathrm{~nm}}^{\mathrm{aer}}=0.2$ and $\tau_{550 \mathrm{~nm}}^{\mathrm{ray}}=0.098$. The vertical grey lines indicate the subset of scattering angles as represented in Figs. 2 to 6 and Fig. 8 .

Table 1. Parameters and their discretisation (in brackets) of the simulated conditions.

\begin{tabular}{ll}
\hline Viewing azimuth angle, $\phi$ & $0^{\circ}, 90^{\circ}, 180^{\circ}$ \\
Viewing zenith angle, $\theta$ & $0^{\circ}, 30^{\circ}, 60^{\circ}$ \\
Solar azimuth angle, $\phi_{0}$ & $180^{\circ}$ \\
Solar zenith angle, $\theta_{0}$ & $0^{\circ}, 15^{\circ}, 30^{\circ}, 45^{\circ}, 60^{\circ}$ \\
Surface albedo, $a_{\lambda}$ & $0.0(0.1) 1.0$ \\
Wavelength, $\lambda$ & $412 \mathrm{~nm}, 550 \mathrm{~nm}, 865 \mathrm{~nm}$ \\
AOD, $\tau 550 \mathrm{~nm}$ & $0.0,0.05,0.1(0.1) 0.5,0.75,1.0$ \\
Sensor-, Target level & TOA, Sea level \\
\hline
\end{tabular}

of a majority of aerosol loadings, except of extreme aerosol events such as dense desert dust outbreaks or volcanic smoke plumes close to the source. For example, Riffler et al. (2010) found, from Aerosol Robotic Network (AERONET, Holben et al., 1998) sun photometer measurements in Europe, that less than $1 \%$ of AOD $(550 \mathrm{~nm})$ exceeds 0.8 . Zhang and Reid (2010) presented similar results from satellite measurements for other regions in the world.

Micro-physical and optical properties of the aerosol models used in the RT calculations are given in Table 2. The continental, urban, and maritime aerosol models are composed from specific mixtures of basic components (water-soluble, soot, dust, and oceanic) described by d'Almeida et al. (1991). The background desert aerosol model was adopted from d'Almeida et al. (1991), the stratospheric volcanic aerosol model from Russell et al. (1996) and the biomass burning aerosol model from Dubovik et al. (2002). The herein used aerosol models span a large range of SSA from highly absorbing (e.g. urban aerosol type with $\omega_{550 \mathrm{~nm}}=0.69$ ) to completely non-absorbing (stratospheric aerosol type with $\omega_{550 \mathrm{~nm}}=1.0$ ). Note that the SSA usually decreases for longer wavelength, except for the desert aerosol type used in this
Table 2. Micro-physical and optical properties of the aerosol models at $550 \mathrm{~nm} . g$ and $\alpha$ denote the asymmetry parameter and Ångström exponent between $412 \mathrm{~nm}$ and $865 \mathrm{~nm}$, respectively. The continental, urban and maritime aerosol models are composed of a mixture of basic aerosol properties (water-soluble, soot, dust, and oceanic) from d'Almeida et al. (1991). The background desert aerosol model was adopted from d'Almeida et al. (1991), the biomass burning model from Dubovik et al. (2002) and the stratospheric model from Russell et al. (1996).

\begin{tabular}{lccccc}
\hline & $\omega_{412 \mathrm{~nm}}$ & $\omega_{550 \mathrm{~nm}}$ & $\omega_{865 \mathrm{~nm}}$ & $g$ & $\alpha$ \\
\hline Continental & 0.901 & 0.893 & 0.857 & 0.619 & 1.327 \\
Maritime & 0.989 & 0.989 & 0.987 & 0.638 & 1.323 \\
Urban & 0.696 & 0.689 & 0.630 & 0.515 & 1.350 \\
Desert & 0.924 & 0.966 & 0.992 & 0.665 & 1.008 \\
Biomass & 0.943 & 0.932 & 0.896 & 0.623 & 2.004 \\
Stratospheric & 1.000 & 1.000 & 1.000 & 0.808 & 0.302 \\
\hline
\end{tabular}

study. The aerosol and Rayleigh phase functions, as well as the corresponding total phase functions, are given in Fig. 1 since $P_{\lambda}$ has a direct influence on atmospheric intrinsic reflectance ( $R_{\lambda}^{\mathrm{ATM}}$, cf. Eq. 2).

\subsection{Critical surface albedo}

The relationship between the modelled TOA reflectance (Eq. 1) as function of surface albedo for a continental aerosol model with different AOD values is shown in Figs. 2 and 3. In general, TOA reflectance increases with increasing AOD for darker surfaces and decreases with increasing AOD for brighter surfaces. This is because aerosol absorption dominates over aerosol scattering if the atmosphere is sufficiently illuminated from below and vice versa. An interesting case occurs where both processes compensate each other, and the TOA reflectance remains almost constant for changing AOD. 


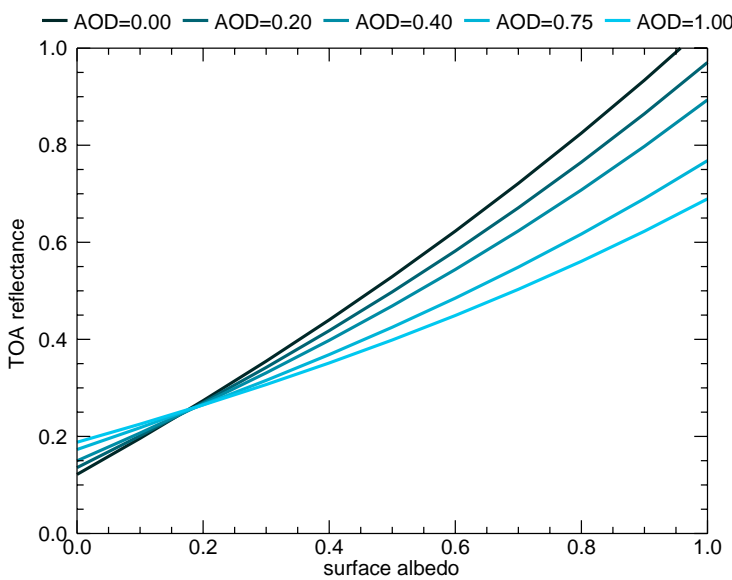

(a) Continental aerosol model at $412 \mathrm{~nm}$

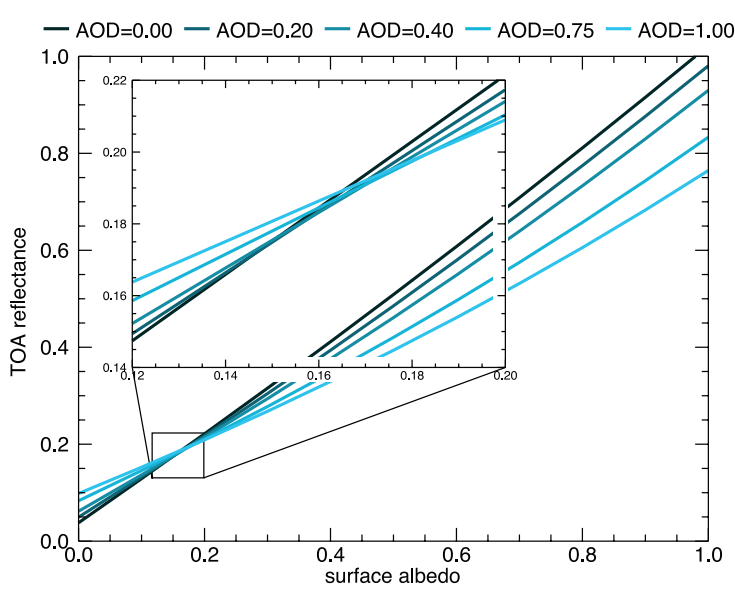

(b) Continental aerosol model at $550 \mathrm{~nm}$

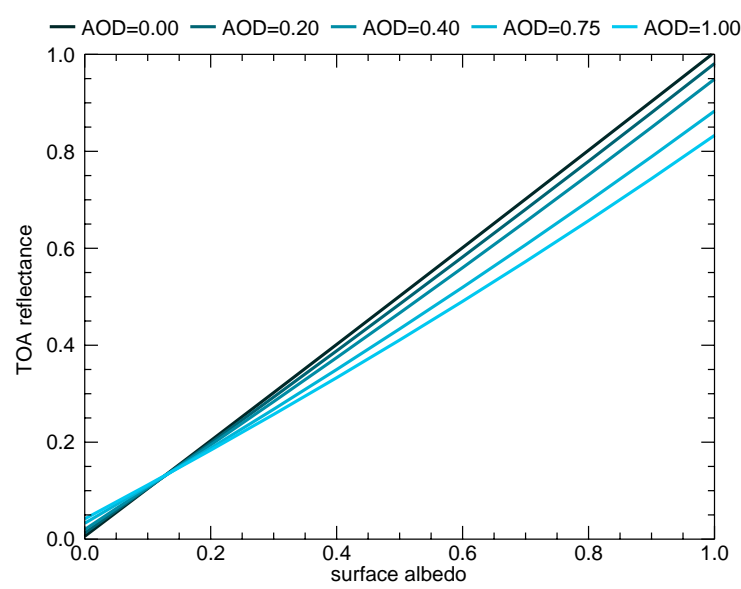

(c) Continental aerosol model at $865 \mathrm{~nm}$

Fig. 2. TOA reflectance (Eq. 1) as function of surface albedo and different AOD values for a continental aerosol type at $412 \mathrm{~nm}$, $550 \mathrm{~nm}$, and $865 \mathrm{~nm}$. Solar zenith angle is $0^{\circ}$, viewing zenith angle $30^{\circ}$ and scattering angle $150^{\circ}$.

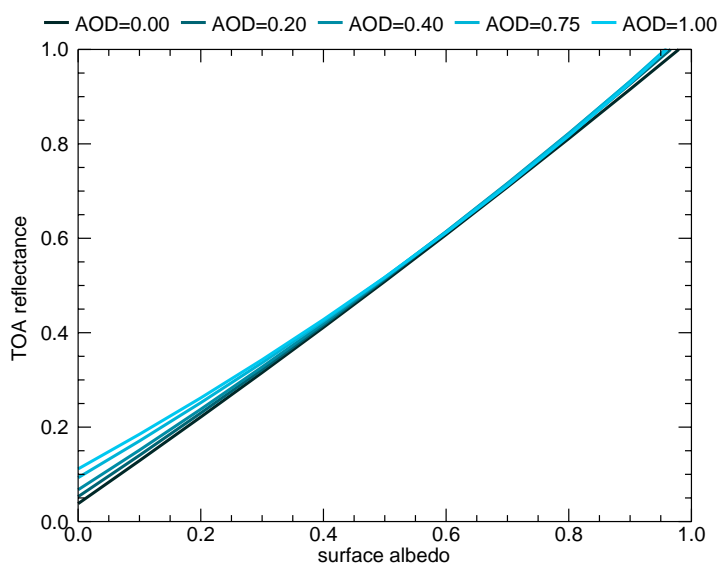

(a) Maritime aerosol model at $550 \mathrm{~nm}$

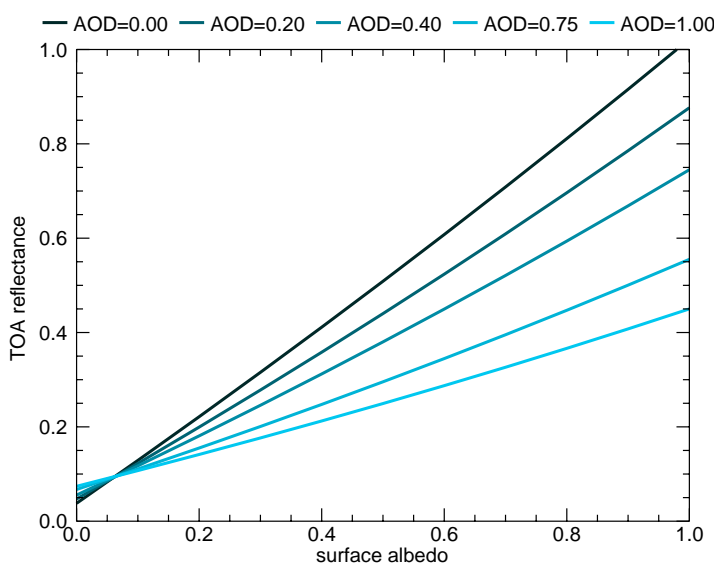

(b) Urban aerosol model at $550 \mathrm{~nm}$

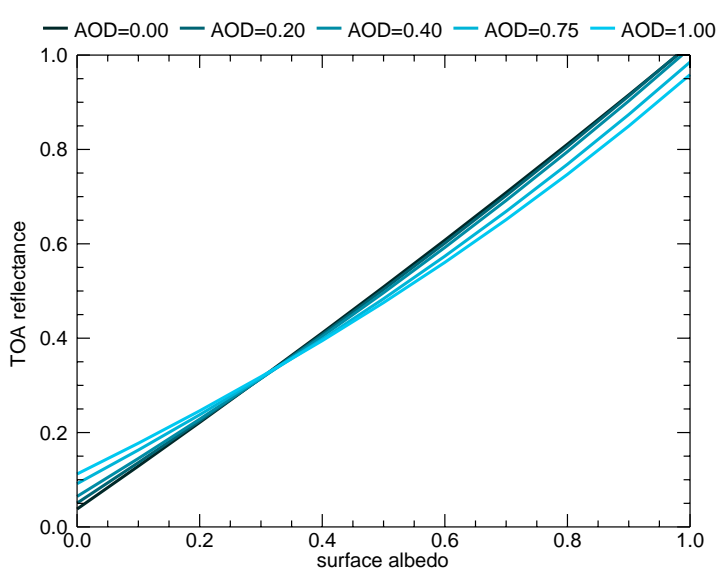

(c) Desert aerosol model at $550 \mathrm{~nm}$

Fig. 3. TOA reflectance (Eq. 1) as function of surface albedo and different AOD values at $550 \mathrm{~nm}$ for different aerosol types. Solar zenith angle is $0^{\circ}$, viewing zenith angle $30^{\circ}$ and scattering angle $150^{\circ}$. 
In other words, this particular surface albedo is "critical" for AOD retrievals, because there is almost no sensitivity of TOA reflectance to AOD. For example, the TOA reflectance in Fig. 2a becomes almost independent of AOD at roughly 0.18 surface albedo, which we define as the CSA.

Previous studies employed the "critical reflectance" as a method for the retrieval of SSA (e.g. Kaufman, 1987; de Almeida Castanho et al., 2008; Zhu et al., 2011; Wells et al., 2012). This method assumes a linear relationship between TOA reflectance and surface albedo, as well as a singular CSA at all AOD values. However, Figs. 2 and 3 show that the TOA reflectance has a non-linear relationship to the surface albedo especially at shorter wavelengths and larger AOD values (cf. Fig. 2a). Figure $2 b$ zooms into the area of CSA to visualise that there is no singular CSA, because the TOA reflectance curves do not cross at exactly the same surface albedo. In theory, $0.5 n(n-1)$ CSA values exist where $n$ denotes the number of TOA reflectance curves. The CSA is therefore also a function of AOD if we account each crossing as a separate CSA value. In reality, the CSA represents a range of surface albedo values given by an ensemble of TOA reflectance crossings. Nevertheless, we use the strict definition of the CSA in this theoretical study in order to enable us to investigate its AOD dependence. Figure 2a to c show that CSA slightly decreases with wavelength for the continental aerosol model due to decreasing SSA with wavelength.

Additional TOA reflectance calculations are provided in Fig. 3 at $550 \mathrm{~nm}$ for a maritime (Fig. 3a), urban (Fig. 3b), and desert (Fig. 3c) aerosol model. Absorbing aerosol types have a much lower CSA, e.g. the urban model with a very low SSA $(550 \mathrm{~nm})$ of 0.69 has the CSA at 0.07 , while the desert model with an SSA $(550 \mathrm{~nm})$ of 0.97 has the CSA at roughly 0.32 .

\subsection{Calculation of the critical surface albedo}

We search for the CSA for which two different AOD $\left(\tau_{\lambda}^{\text {aer }}\right)$ values lead to the same TOA reflectance, such that

$$
\begin{aligned}
& R_{\lambda}^{\mathrm{TOA}}\left(\tau_{\lambda}^{\mathrm{aer} 1}, a_{\lambda}=\mathrm{CSA}\right)- \\
& R_{\lambda}^{\mathrm{TOA}}\left(\tau_{\lambda}^{\mathrm{aer} 2}, a_{\lambda}=\mathrm{CSA}\right) \equiv 0 .
\end{aligned}
$$

The CSA retrieval is simplified by fitting a fifth-order polynomial to a TOA reflectance (Eq. 1, Figs. 2 and 3) providing a continuous and differentiable function:

$$
R_{\lambda}^{\mathrm{TOA}}\left(\tau_{\lambda}^{\mathrm{aer}}, a_{\lambda}\right) \approx \sum_{i=0}^{5} c_{i}\left[\tau_{\lambda}^{\mathrm{aer}}\right]^{i}
$$

where $c_{i}$ denotes the polynomial coefficients of order $i$. The average reflectance fitting error is less than 0.0002 absolute reflectance values. The sensitivity of the TOA reflectance to AOD is derived by its partial derivative with respect to AOD:

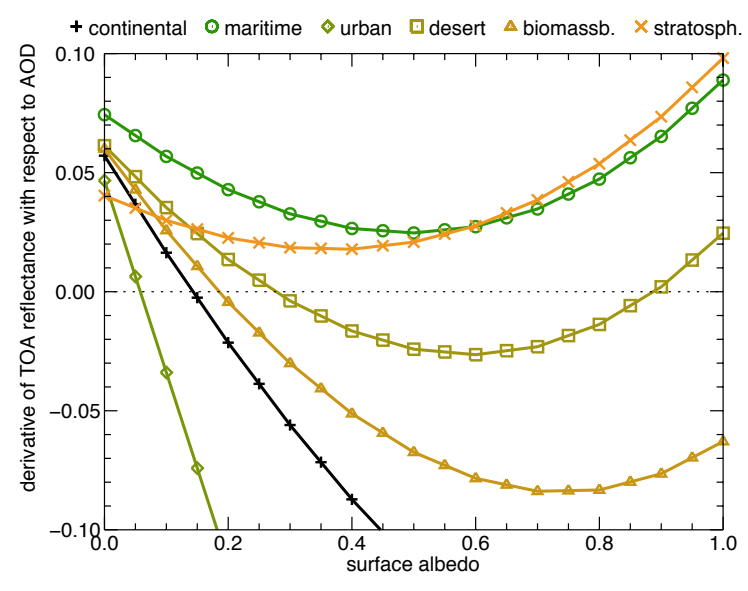

(a) $\mathrm{AOD}=0.05$

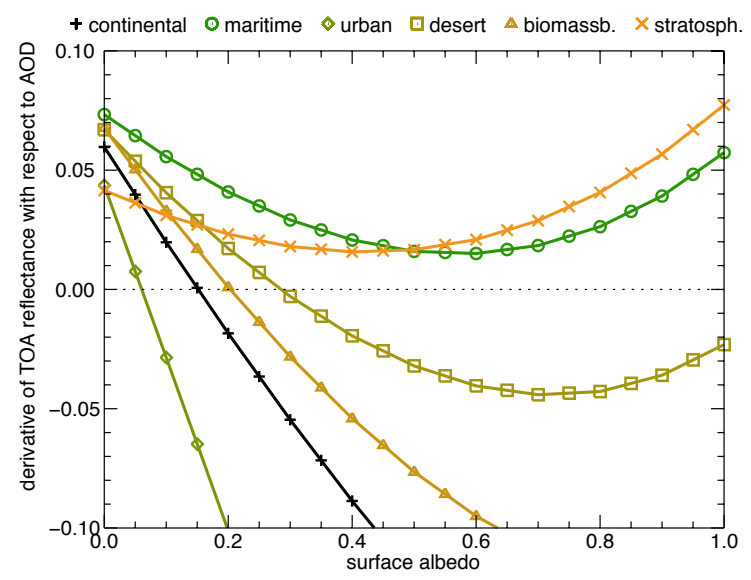

(b) $\mathrm{AOD}=0.2$

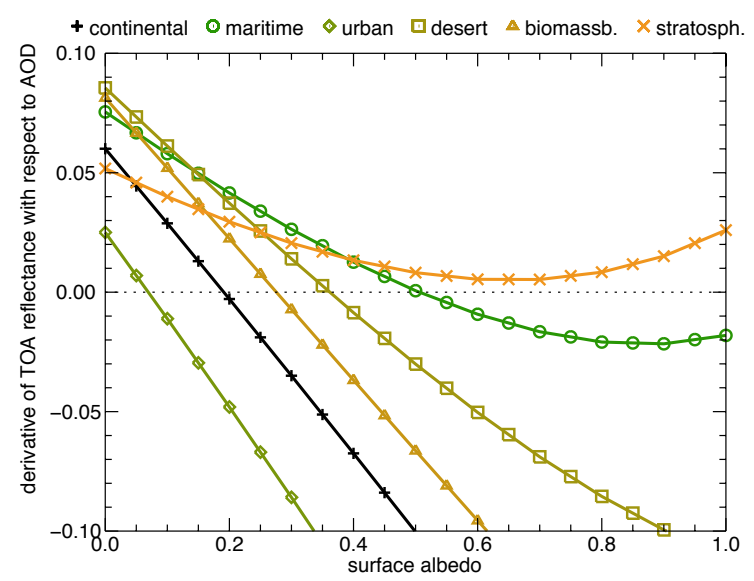

(c) $\mathrm{AOD}=1.0$

Fig. 4. Derivative of TOA reflectance with respect to AOD as a function of surface albedo for different aerosol models at $550 \mathrm{~nm}$. 


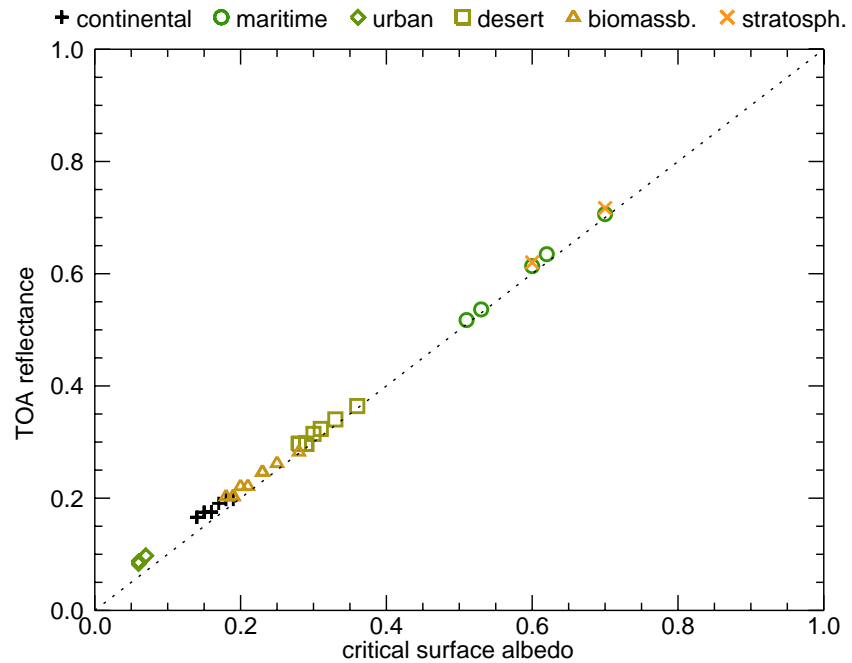

Fig. 5. TOA reflectance $R_{550 \mathrm{~nm}}^{\mathrm{TOA}}\left(\tau_{550 \mathrm{~nm}}^{\mathrm{aer}} \in[0.0,0.05,0.1(0.1) 0.5\right.$, $0.75,1.0]$ ) according to Eq. (1) as a function of CSA at $550 \mathrm{~nm}$. Solar zenith angle is $0^{\circ}$, viewing zenith angle $30^{\circ}$ and scattering angle $150^{\circ}$.

$$
\frac{\partial R_{\lambda}^{\mathrm{TOA}}\left(\tau_{\lambda}^{\mathrm{aer}}, a_{\lambda}\right)}{\partial \tau_{\lambda}^{\mathrm{aer}}} \approx \sum_{i=1}^{5} i c_{i}\left[\tau_{\lambda}^{\mathrm{aer}}\right]^{i-1} .
$$

Finally, the CSA is derived by finding the surface albedo:

$$
\frac{\partial R_{\lambda}^{\mathrm{TOA}}\left(\tau_{\lambda}^{\mathrm{aer}}, a_{\lambda}=\mathrm{CSA}\right)}{\partial \tau_{\lambda}^{\mathrm{aer}}}:=0 .
$$

The retrieved CSA is a function of the observation and illumination geometry, wavelength, aerosol properties and AOD. The sensitivities of the CSA to these parameters are examined in Sect. 3. Results from Eq. (9) using six aerosol models at $550 \mathrm{~nm}$ are plotted in Fig. 4 for three different values of AOD. In general, this relationship is almost linear for aerosol types with moderate to strong absorption characteristics (e.g. urban or continental) and becomes non-linear for weakly or non-absorbing aerosol models. The CSA for the different models can be found at the interception with $y=0$ (dotted line). Low or non-absorbing aerosol types indicate no CSA for $\tau_{\lambda}^{\text {aer }} \lesssim 0.5$ (e.g. maritime and stratospheric in Fig. 4a and b). Smirnov et al. (2011) found that AOD over oceans in the absence of continental outflow with dust or pollution rarely exceeds 0.2 , which favours the relatively high sensitivity of aerosol retrievals over oceans for typical maritime conditions. Interestingly, the desert aerosol model in Fig. 4a reveals two different CSAs (approximately at 0.3 and 0.9 ). Further, it is noteworthy that the CSA changes with AOD, especially and most pronounced for the scattering aerosol types. For example, the CSA for the desert aerosol $\left(\omega_{550} \mathrm{~nm}=0.97\right)$ increases from 0.3 with $\mathrm{AOD}=0.05$ (Fig. $4 \mathrm{a}$ ) to 0.35 with $\mathrm{AOD}=0.2$ (Fig. 4b) and 0.4 with $\mathrm{AOD}=1.0$ (Fig. 4c).

\section{Results}

\subsection{Sensitivity analysis}

\subsubsection{Sensitivity of top-of-atmosphere reflectance to critical surface albedo}

The surface contribution $R_{\lambda}^{\mathrm{SFC}}$ (Eq. 6) dominates the TOA reflectance (Eq. 1), except in the case of very dark surfaces and short wavelengths $(\lambda \lesssim 500 \mathrm{~nm})$ and therefore is $R_{\lambda}^{\mathrm{TOA}} \sim a_{\lambda}$. Figure 5 shows that the CSA is just slightly below the TOA reflectance because $R_{\lambda}^{\mathrm{ATM}}<R_{\lambda}^{\mathrm{SFC}}$. The different AOD and aerosol models (see Table 2) have an effect on the absolute value of $R_{\lambda}^{\mathrm{TOA}}$ but not much on the relative dependence between $R_{\lambda}^{\mathrm{TOA}}$ and the corresponding CSA.

Each point in Fig. 5 corresponds to an intersection of two $R^{\mathrm{TOA}}$ curves in Figs. $2 \mathrm{~b}$ and 3 . The distribution of the intersections depends on aerosol absorption and therefore on the aerosol model. Lower SSA corresponds to lower CSA and vice versa. For example, the urban aerosol model $\left(\omega_{550 \mathrm{~nm}}=0.69\right)$ has a CSA of about 0.05 , while the nonabsorbing maritime and stratospheric aerosol types have a CSA higher than 0.7. The positions of the different points along the bisecting line depend on AOD (see also Sect. 2.3). The sensitivity to AOD is weaker for absorbing aerosols, and thus the CSA of the urban and continental model are close together for all analysed AOD. Generally, the CSA of the different aerosol models is well separated for the given range of AOD values, except for the non-absorbing maritime and stratospheric aerosol models. This finding is important for the determination of aerosol types from TOA reflectance measurements.

\subsubsection{Sensitivity of critical surface albedo to single-scattering albedo}

The CSA depends strongly on the aerosol absorption efficiency or SSA ( $\left.\omega_{\lambda}^{\text {aer }}\right)$ (cf. Eq. 3 as well as Fraser and Kaufman, 1985; Kaufman, 1987). The relation between CSA and SSA is shown in Fig. 6. Generally, lower SSA (stronger aerosol absorption) leads to lower CSA. However, the solar and observational geometry with the corresponding scattering angle, and therewith the aerosol phase function, has an influence on CSA (as shown by Fig. 6). The CSA is almost spectrally invariant for absorbing aerosols. Low absorbing aerosols with $\omega_{\lambda}^{\text {aer }}>0.9$ have generally higher CSA at $412 \mathrm{~nm}$ as compared to $865 \mathrm{~nm}$. In contrast, the desert aerosol model CSA is lower at $412 \mathrm{~nm}$ than $865 \mathrm{~nm}$. According to these results, the CSA could be parametrised with respect to SSA and used for the determination of aerosol types from TOA reflectance measurements as mentioned before and demonstrated in de Almeida Castanho et al. (2008), Zhu et al. (2011), and Wells et al. (2012). 


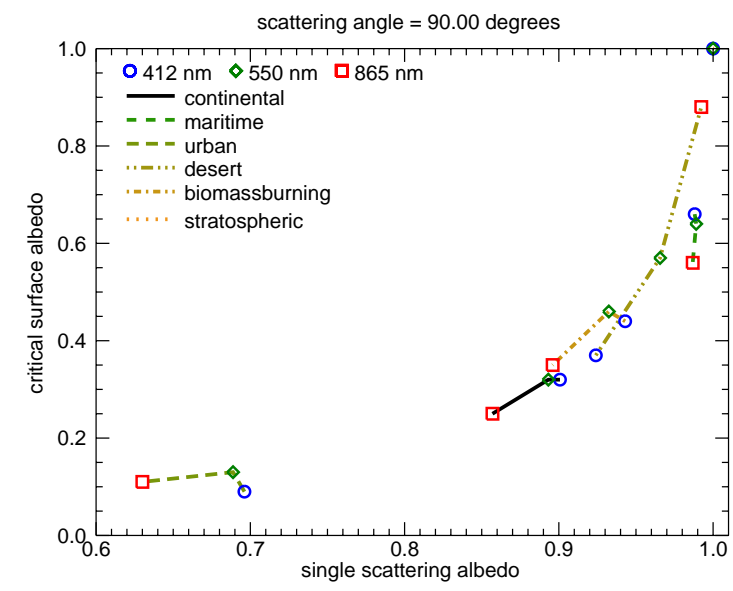

(a) $\phi=0^{\circ}, \theta_{0}=30^{\circ}, \theta=60^{\circ}, \Theta=90^{\circ}$

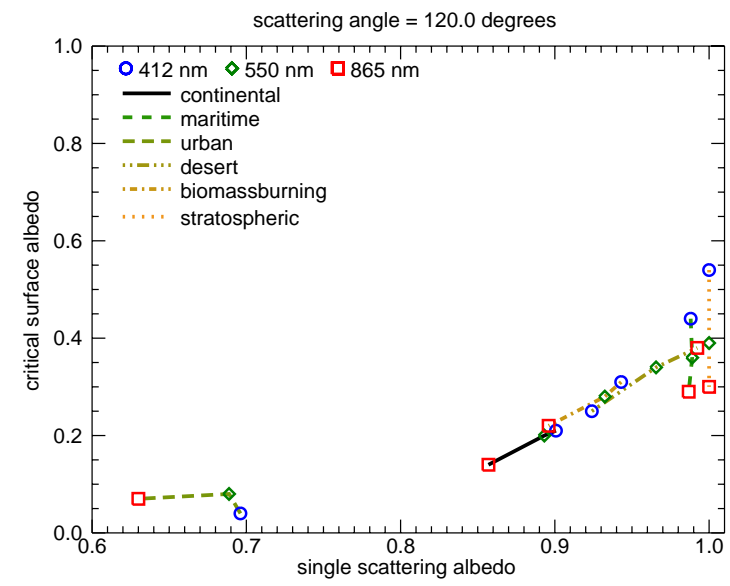

(c) $\phi=0^{\circ}, \theta_{0}=0^{\circ}, \theta=60^{\circ}, \Theta=120^{\circ}$

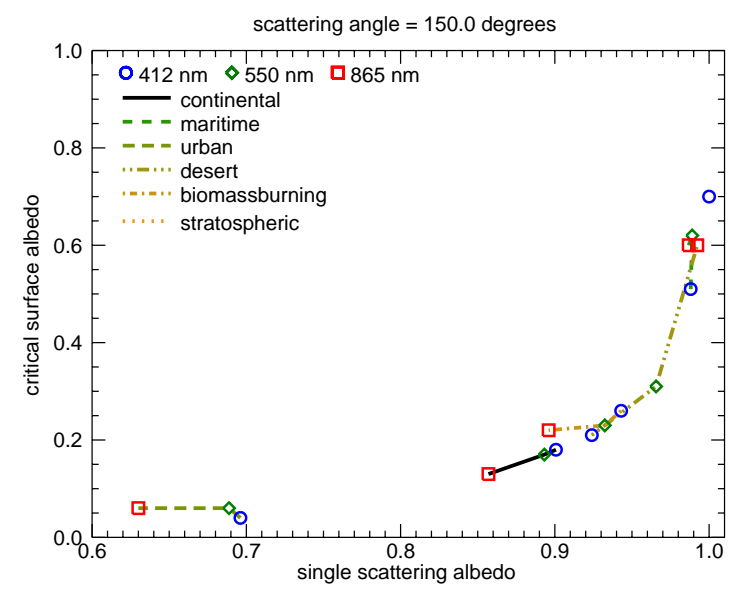

(e) $\phi=0^{\circ}, \theta_{0}=0^{\circ}, \theta=30^{\circ}, \Theta=150^{\circ}$

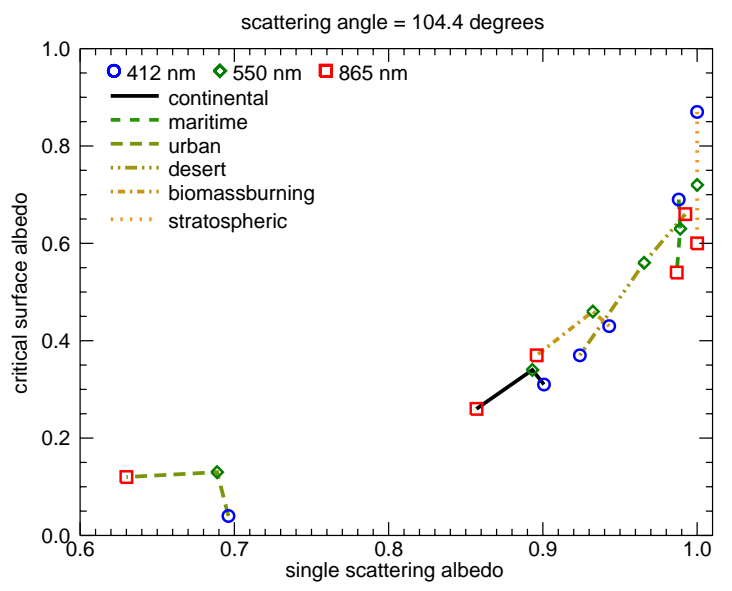

(b) $\phi=90^{\circ}, \theta_{0}=60^{\circ}, \theta=60^{\circ}, \Theta=104^{\circ}$

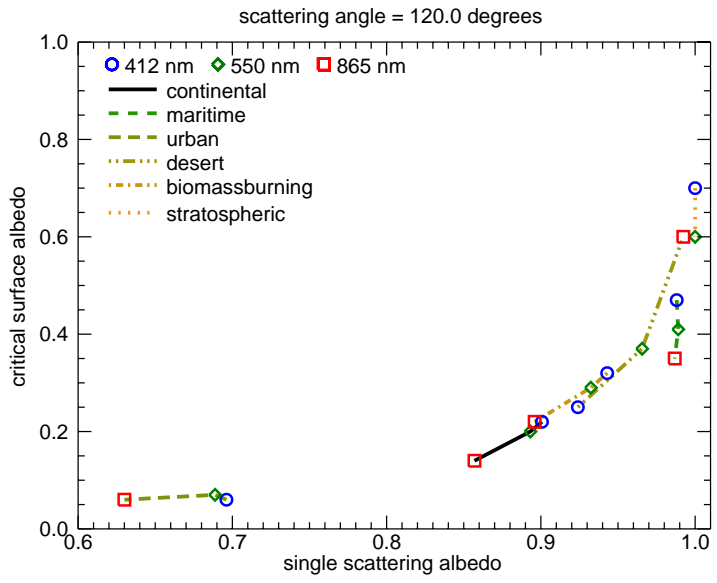

(d) $\phi=0^{\circ}, \theta_{0}=30^{\circ}, \theta=30^{\circ}, \Theta=120^{\circ}$

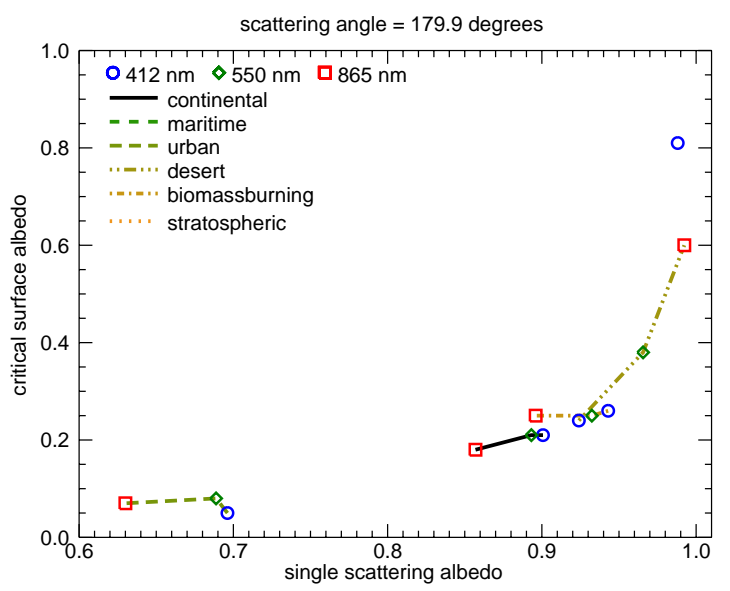

(f) $\phi=180^{\circ}, \theta_{0}=30^{\circ}, \theta=30^{\circ}, \Theta=179^{\circ}$

Fig. 6. CSA as function of SSA for $\mathrm{AOD}=0.2$ at $412 \mathrm{~nm}, 550 \mathrm{~nm}$ and $865 \mathrm{~nm}$, as well as for different aerosol types and different combinations of viewing azimuth angle $\phi$, solar zenith angle $\theta_{0}$, viewing zenith angle $\theta$ and the corresponding scattering angle $\Theta$. 


\subsubsection{Sensitivity of critical surface albedo to observation and solar geometry}

CSA values are given in Fig. 7 as a function of scattering angle, which corresponds to a combination of VAA, VZA, SZA according to Eq. (5). Some combinations have a common scattering angle, which leads to multiple results per scattering angle in Fig. 7. Interestingly, SSA seems to have an influence on the separation of these results. Absorbing aerosols with $\omega<0.95$ show a relatively distinct relation between CSA and the scattering angle (Fig. 7a). Low and nonabsorbing aerosol types with $\omega>0.95$ show much more sensitivity of CSA to different solar- and viewing geometries and therefore different path lengths through the atmosphere (Fig. 7b). Generally, Fig. 7 shows that CSA depends on the scattering phase function (cf. Fig. 1) as well as the SSA. The CSA has therefore smaller values in the range of scattering angles $\Theta \in\left[110^{\circ}, 150^{\circ}\right]$, which corresponds to typical observation geometries of many remote sensing instruments. The minimum for the CSA corresponds also to the minimum in the aerosol phase functions $\left(\simeq 120^{\circ}\right)$. Backward scattering geometries have significantly larger CSA. Some aerosol types have no CSA in the forward scattering direction (see Fig. 7).

\subsubsection{Sensitivity of critical surface albedo to aerosol optical depth}

The findings above show that CSA can slightly depend on AOD and that, in fact, CSA often represents a small range of surface albedo values with minimal sensitivity to AOD. Figure 8 illustrates the relation between CSA and AOD in more details. Figure 8a to d show distinct increases in CSA for larger AOD, except for absorbing aerosol types with $\omega_{550 \mathrm{~nm}} \leq 0.9$ (i.e. urban and continental). CSAs at larger scattering angles (Fig. 8e to f) are found to depend less on AOD.

\subsection{Implications to aerosol remote sensing}

The results of this study have several significant implications for the remote sensing of aerosols from satellite observations.

\subsubsection{Implication to aerosol optical depth retrieval}

The AOD retrieval error as a function of surface albedo for an under- and overestimation of surface albedo of 0.01 for different aerosol types is shown in Fig. 9. We define the AOD retrieval error as $\tau_{\text {true }}^{\text {aer }}-\tau_{\text {retrieved }}^{\text {aer }}$ with $\tau_{\text {true }}^{\text {aer }}=0.3$ in this example. We extract $\tau_{\text {retrieved }}^{\text {aer }}$ from the lookup table (LUT) (cf. Sect. 2.2 and Table 1) by searching for the AOD corresponding to the varying surface albedo (of \pm 0.01 ) while keeping other model parameters constant.

Seidel et al. (2011), Sects. 2.3 and 2.4 have shown that the TOA reflectance is insensitive to AOD at the CSA and that it is therefore not possible to retrieve AOD from a single

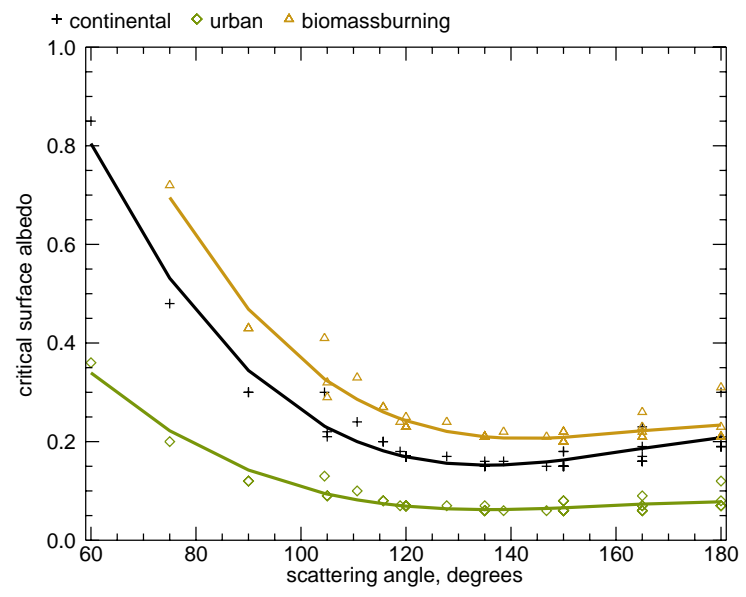

(a) Low SSA $(\omega<0.95)$

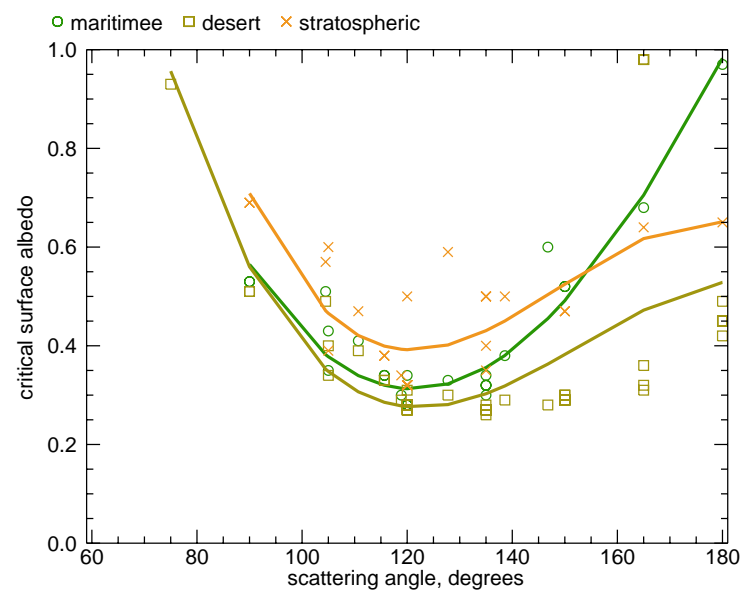

(b) High SSA $(\omega>0.95)$

Fig. 7. $\mathrm{CSA}$ as a function of scattering angle for $\mathrm{AOD}=0.2$ at $550 \mathrm{~nm}$. Certain combinations of solar and observing geometries have the same scattering angle, which leads to multiple results per aerosol model, especially for less absorbing aerosol types. The solid lines provide a polynomial fit to the retrieved CSA.

optical measurement at this surface albedo. This is demonstrated in Fig. 9 with AOD retrieval errors rising towards the CSA (indicated by the vertical red line). AOD retrieval errors close the the CSA are exceptionally high and usually exceeding $100 \%$, although the simulated error of the surface albedo is small with 0.01 .

In general, for surface albedo values smaller than the CSA, an overestimation of the surface albedo leads to an underestimation of AOD and therefore a positive retrieval error in our examples. The opposite is the case for surface albedo values higher than the CSA, where the overestimation of the surface albedo leads to an overestimation of AOD and thus a negative retrieval error. The latter is due to the decrease in TOA reflectance by increasing AOD over bright surfaces. 


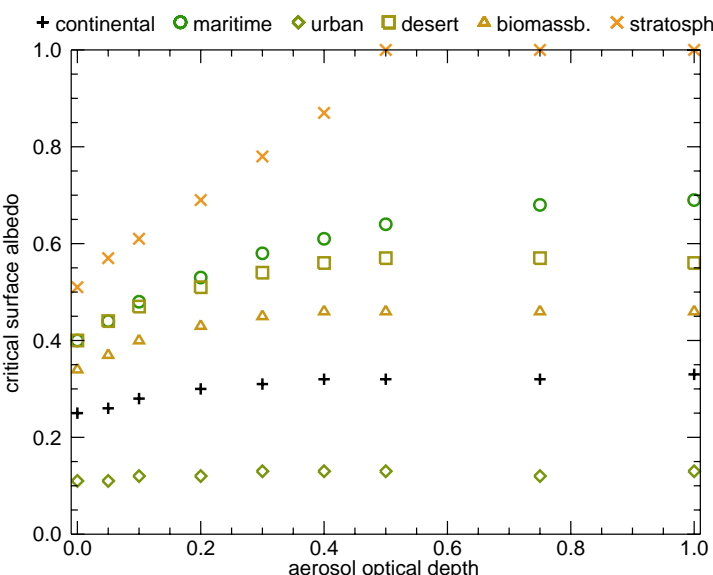

(a) $\phi=0^{\circ}, \theta_{0}=30^{\circ}, \theta=60^{\circ}, \Theta=90^{\circ}$

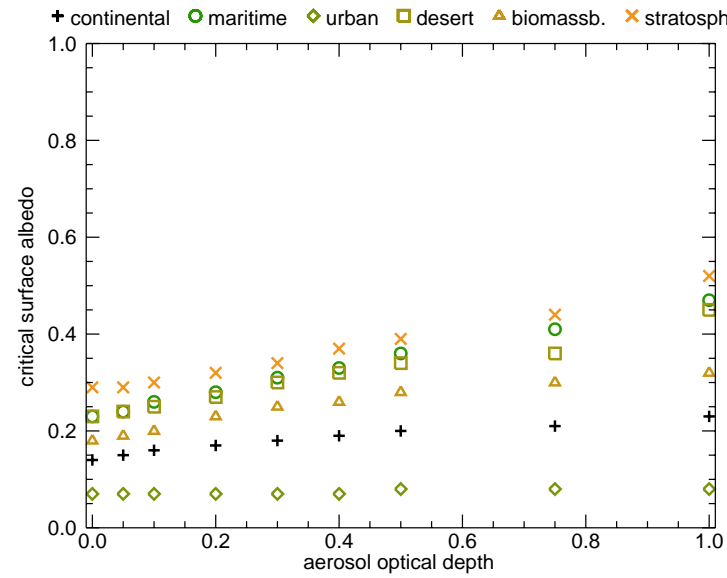

(c) $\phi=0^{\circ}, \theta_{0}=0^{\circ}, \theta=60^{\circ}, \Theta=120^{\circ}$

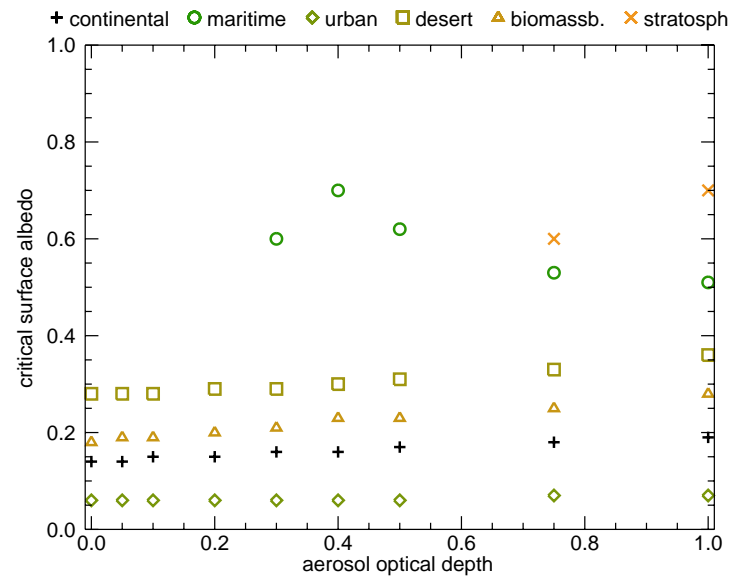

(e) $\phi=0^{\circ}, \theta_{0}=0^{\circ}, \theta=30^{\circ}, \Theta=150^{\circ}$

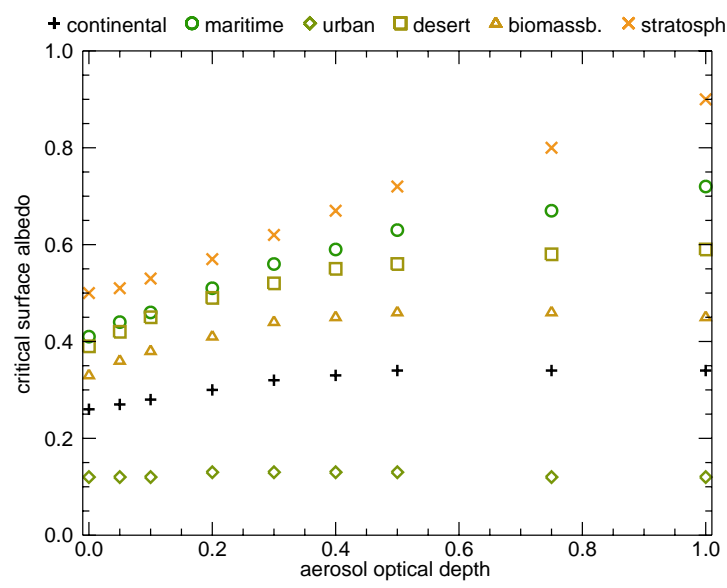

(b) $\phi=90^{\circ}, \theta_{0}=60^{\circ}, \theta=60^{\circ}, \Theta=104^{\circ}$

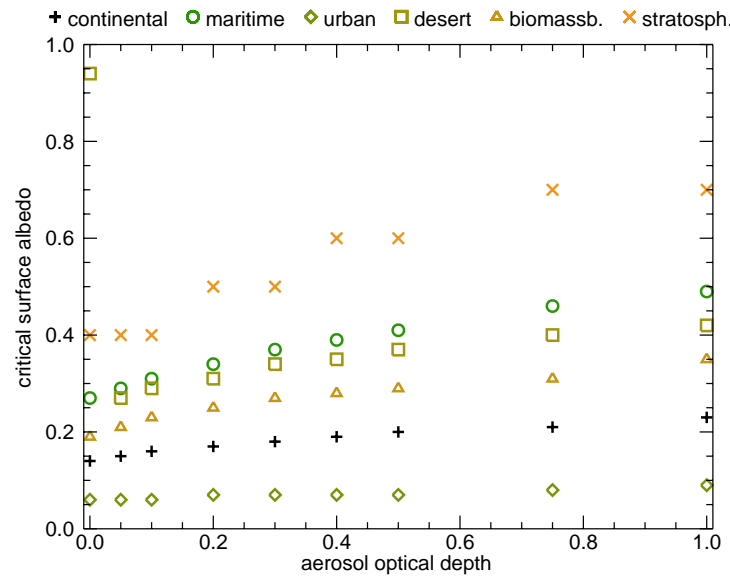

(d) $\phi=0^{\circ}, \theta_{0}=30^{\circ}, \theta=30^{\circ}, \Theta=120^{\circ}$

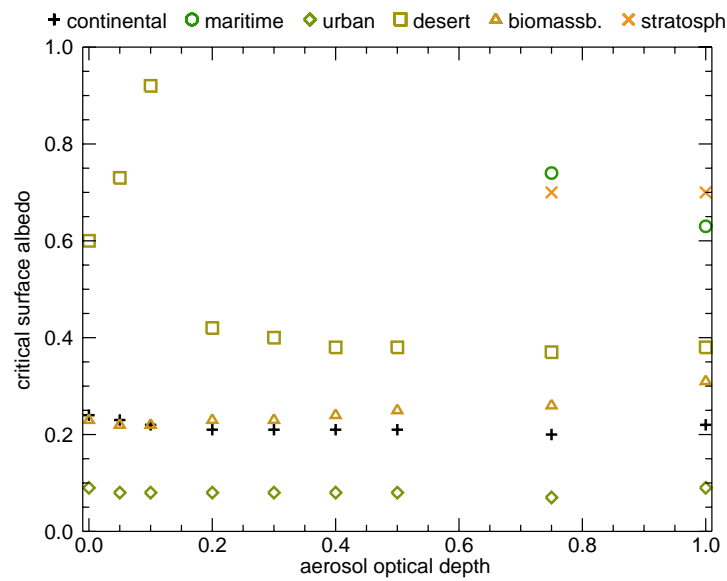

(f) $\phi=180^{\circ}, \theta_{0}=30^{\circ}, \theta=30^{\circ}, \Theta=179^{\circ}$

Fig. 8. Critical surface albedo as function of AOD at $550 \mathrm{~nm}$ for different aerosol types and different combinations of viewing azimuth $\phi$, solar zenith $\theta_{0}$ and viewing zenith angles $\theta$, as well as the corresponding scattering angle $\Theta$. 
Especially for aerosol models with high and moderate absorption characteristics (Fig. 9a, c, and e), the AOD retrieval errors over bright surfaces are surprisingly low $(<0.05$ or $\sim 15 \%$ ). This suggests that bright surfaces, such as snow and ice or clouds, are ideal to retrieve AOD of absorbing aerosols with $\omega_{\lambda}^{\text {aer }}<0.9$, e.g. black carbon. Bright desert regions, a major natural source of atmospheric aerosols, have often a surface albedo close to the CSA, which turns out to be very challenging for spaceborne AOD retrievals or the derivation of albedo products in deserted areas of the world (e.g. Popp et al., 2011). Knowledge about the CSA might help to improve both AOD and SSA retrievals in arid regions and might indirectly (e.g. through atmospheric correction) lead to better albedo products in arid regions derived from remote sensing data. Our results show also that the AOD of less absorbing aerosols with $\omega_{\lambda}^{\text {aer }}>0.9$ can be retrieved over dark surfaces with $a_{\lambda} \leq 0.2$ because their CSA is far from the surface albedo of many surfaces, such as water, vegetation, soil, asphalt and others.

However, the observation and solar geometry must be taken into account to avoid the CSA in AOD retrievals. In practice, scattering angles of less than $110^{\circ}$ should be favoured in AOD retrievals over dark targets and scattering angles around $120^{\circ}$ are ideal for retrievals over surfaces with an albedo of more than 0.5 . Small scattering angles are given for nadir observation geometries at sunrise and sunset.

Finally, the AOD retrieval accuracy depends also on additional parameters not considered in the modelling study, such as gaseous absorption, accuracy of auxiliary data, or the sensor performance and measuring accuracy (Seidel et al., 2008).

\subsubsection{Implication to single-scattering albedo retrieval}

Figure 6 shows the non-linear spectral dependence of SSA, such that $\omega_{412 \mathrm{~nm}} \approx \omega_{550 \mathrm{~nm}}>\omega_{865 \mathrm{~nm}}$ for absorbing aerosol types $(\omega<0.93)$ and $\omega_{412 \mathrm{~nm}} \approx \omega_{550 \mathrm{~nm}} \approx \omega_{865 \mathrm{~nm}}$ for weakly absorbing aerosols $(\omega>0.93)$. An initial retrieval of CSA or its estimation from a LUT potentially provides a good strategy to determine the SSA, which allows to estimate a corresponding aerosol model.

According to the findings in Sect. 3.1.2, a polynomial fit to the CSA as a function of SSA could be used to identify the SSA corresponding to a retrieved CSA (see Fig. 6). Our results could potentially help to improve existing methods to estimate SSA using critical reflectance methods (Kaufman, 1987; de Almeida Castanho et al., 2008; Zhu et al., 2011). The difference of our analysis to the studies mentioned above is that we do not assume a linear relationship between TOA reflectance and AOD or between surface albedo and TOA reflectance. As a consequence, we calculate the CSA by determining the derivative of TOA reflectance with respect to AOD. This might allow to expand the derivation of SSA to cases where a linear fit fails or is prone to fitting errors. Nevertheless, an accurate determination of SSA using remote sensing is still a difficult task but promises to distinguish between absorbing and less or non-absorbing aerosol types.

\subsubsection{Implication to atmospheric correction}

Atmospheric correction of satellite images is an important prerequisite to obtain surface properties for many remote sensing applications. Often, aerosol micro-physical and optical properties are unknown and therefore assumed prior to the atmospheric correction. The presented results show clearly that uncertainties in surface albedo estimations have a strong impact on AOD retrievals. On the other hand, an inaccurate estimate of the AOD will have a much smaller effect on the accuracy of atmospherically corrected reflectance if the surface albedo is around the CSA than if the surface albedo is much lower or higher than the CSA because of the weak sensitivity of the TOA reflectance to AOD around the CSA.

\section{Summary and conclusions}

With this work, we provide a sensitivity analysis of the reflectance at TOA as function of surface albedo to AOD, as well as of the resulting CSA to various parameters. We determine the CSA with partial derivatives of the reflectance at TOA with respect to AOD, whereas most previous studies (Fraser and Kaufman, 1985; Kaufman, 1987; de Almeida Castanho et al., 2008; Zhu et al., 2011) assumed linear relations between these two quantities. This allows us to conclude that the CSA depends mainly on SSA, scattering angle and wavelength. It depends to a minor degree also on AOD, except for strong absorbing aerosol types and for scattering angles larger than $150^{\circ}$. We therefore propose to extend the definition of CSA to the more general case where the CSA represents a small surface albedo range with minimal AOD sensitivity.

AOD retrievals over surfaces with a reflectance factor or albedo close to the CSA will result in large errors due to the low sensitivity of the observed quantity (radiance or intensity at TOA) to the retrieved quantity. Thus, small inaccuracies of the estimated surface albedo lead to large AOD retrieval errors. For example, soil and desert surfaces often have albedo values close to the CSA of moderately absorbing aerosols, where 0.01 albedo uncertainty leads to at least 0.1 AOD retrieval error. On the other side, we showed that the retrieval error is rather small for absorbing aerosols over bright surfaces. This offers interesting opportunities for deriving AOD over snow or clouds. The CSA may be even used in theory to determine the aerosol type from TOA reflectance measurements, because the CSA values depend strongly on SSA, which are well separated for different aerosol models, except for the non-absorbing particles. Furthermore, conditions close and at the CSA reduce the impact of AOD uncertainties in atmospherically corrected remote sensing data. 


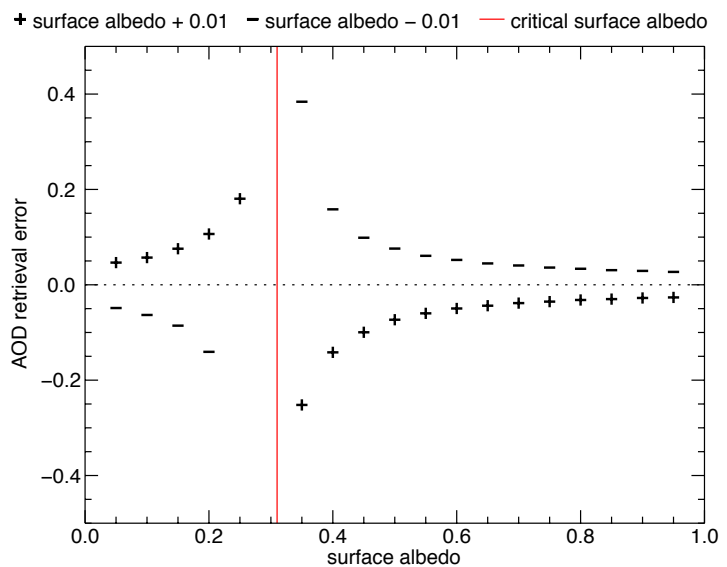

(a) Continental aerosol model

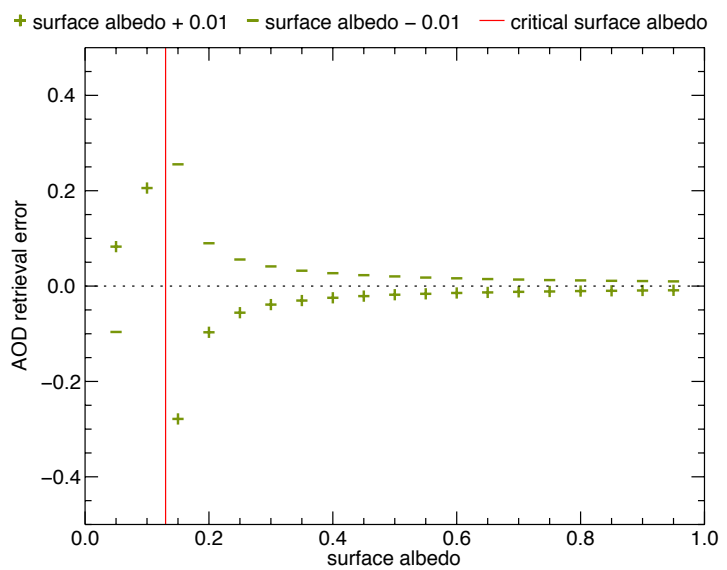

(c) Urban aerosol model

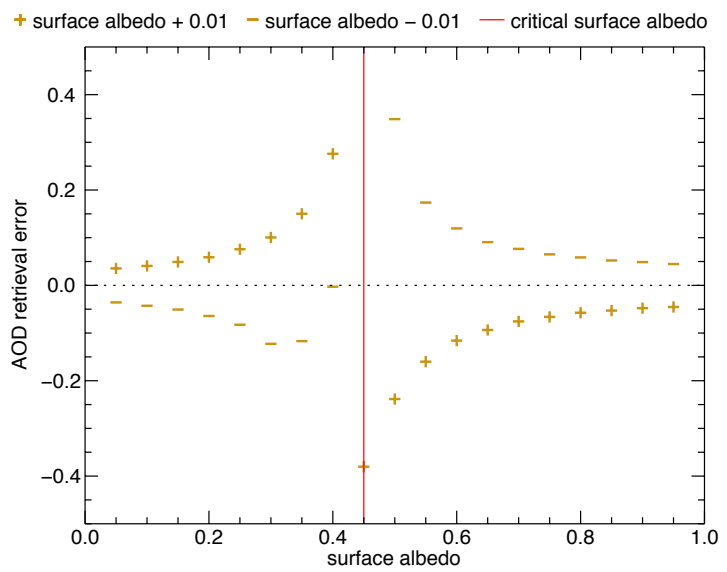

(e) Biomass burning aerosol model

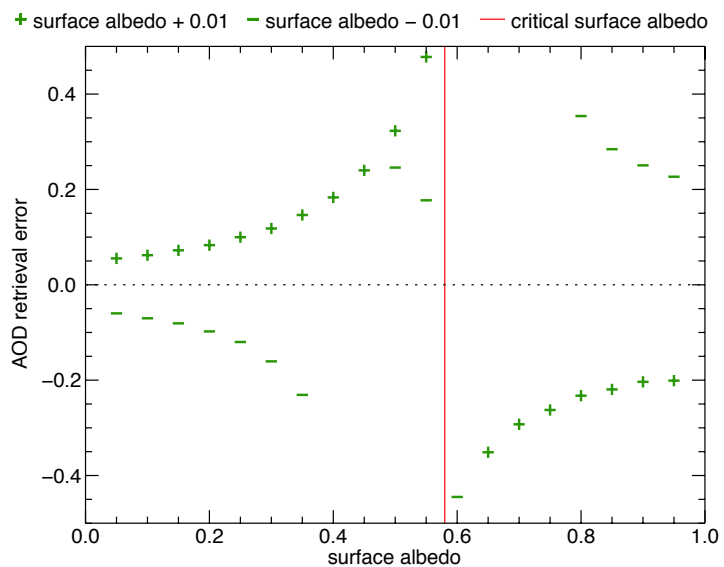

(b) Maritime aerosol model

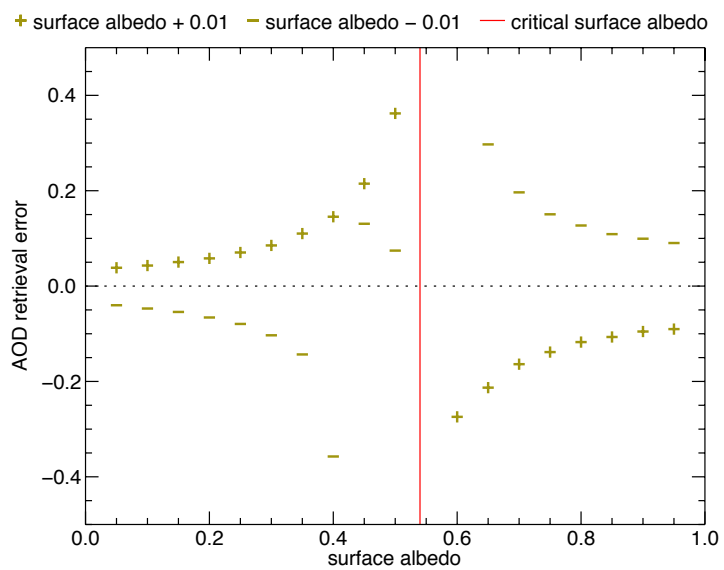

(d) Desert aerosol model

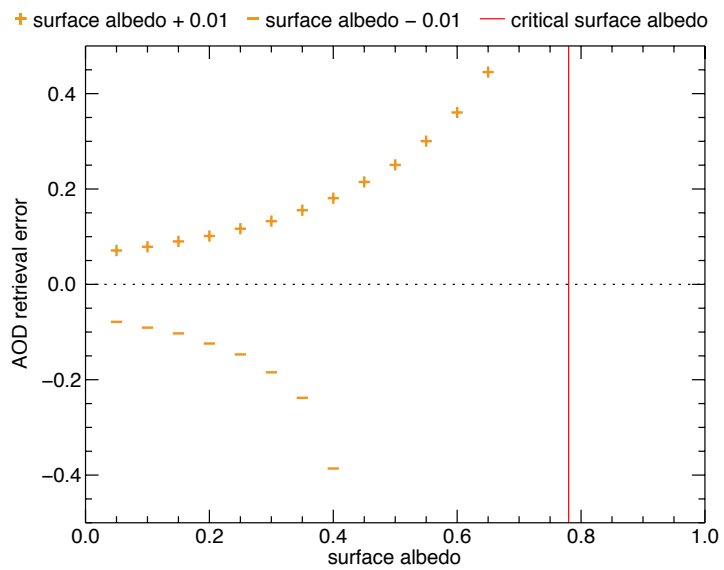

(f) Stratospheric aerosol model

Fig. 9. AOD retrieval error $\left(\tau_{\text {true }}^{\text {aer }}-\tau_{\text {retrieved }}^{\text {aer }}\right)$ as a function of surface albedo at $550 \mathrm{~nm}$ for different aerosol types with $\tau_{\text {true }}^{\text {aer }}=0.3$ at $\phi=0^{\circ}$, $\theta_{0}=30^{\circ}$, and $\theta=30^{\circ}$. The plus signs denote an overestimation of surface albedo by +0.01 and the minus signs an underestimation of surface albedo by -0.01 . The CSA is provided by the red line. 
The results in this paper suggest that AOD retrievals close to the CSA will be prone to large errors for single-view and intensity-only observations. Such retrievals could be problematic in terms of fast convergence and finding the global minima with the correct solution. We recommend to include a priori information on the sensitivity of the measured radiance to AOD in retrieval algorithms similar to the retrieval schemes outlined in Govaerts et al. (2010) and Sayer et al. (2012). It could help to avoid unnecessary computation time and would allow to include error estimations in the final product. Finally, the presented findings allow to investigate AOD retrieval sensitivities for single-view, intensity-only spaceborne instruments with given solar and observation geometries, as well as surface and aerosol climatologies.

Acknowledgements. The work of F. C. Seidel for the AMTD version of this study was performed at the Remote Sensing Laboratories, University of Zurich, Switzerland, and for AMT at the Jet Propulsion Laboratory, California Institute of Technology, under a contract with the National Aeronautics and Space Administration. The author's copyright for this publication is transferred to the California Institute of Technology. Government Sponsorship acknowledged. C. Popp acknowledges Hyper-Swiss-Net which is jointly funded by the Swiss University Conference and the ETH Board as an Innovation/Cooperation project (Reference number C-19). We are very grateful for the thoughtful comments and suggestions by Alexander A. Kokhanovsky and two anonymous reviewers, which helped to considerably improve our manuscript.

Edited by: J. Cermak

\section{References}

Ångström, A.: The albedo of various surfaces of ground, Geogr. Ann., 7, 323-342, 1925.

Brunekreef, B. and Holgate, S. T.: Air pollution and health, The Lancet, 360, 1233-1242, 2002.

Chandrasekhar, S.: Radiative Transfer, Dover, New York, USA, 1960.

d'Almeida, G., Koepke, P., and Shettle, E.: Atmospheric aerosols: global climatology and radiative characteristics, Deepak, Hampton, Virginia, USA, 1991.

de Almeida Castanho, A. D., Vanderlei Martins, J., and Artaxo, P.: MODIS Aerosol Optical Depth Retrievals with high spatial resolution over an Urban Area using the Critical Reflectance, J. Geophys. Res., 113, D02201, doi:10.1029/2007JD008751, 2008.

Dubovik, O., Holben, B., Eck, T. F., Smirnov, A., Kaufman, Y. J., King, M. D., Tanré, D., and Slutsker, I.: Variability of Absorption and Optical Properties of Key Aerosol Types Observed in Worldwide Locations, J. Atmos. Sci., 59, 590-608, 2002.

Fraser, R. S. and Kaufman, Y. J.: The relative importance of aerosol scattering and absorption in remote sensing, IEEE J. Geosci. Remote, GE-23, 525-633, 1985.

Govaerts, Y. M., Wagner, S., Lattanzio, A., and Watts, P.: Joint retrieval of surface reflectance and aerosol optical depth from MSG/SEVIRI observations with an optimal estima- tion approach: 1. Theory, J. Geophys. Res., 115, D02203, doi:10.1029/2009JD011779, 2010.

Holben, B. N., Eck, T. F., Slutsker, I., Tanre, D., Buis, J. P., Setzer, A., Vermote, E., Reagan, J. A., Kaufman, Y. J., Nakajima, T., Lavenu, F., Jankowiak, I., and Smirnov, A.: AERONET - A federated instrument network and data archive for aerosol characterization, Remote Sens. Environ., 66, 1-16, 1998.

IPCC - Intergovernmental Panel on Climate Change: Climate Change 2007: The Physical Science Basis, edited by: Solomon, S., Qin, D., Manning, M., Chen, Z., Marquis, M., Averyt, K. B., Tignor, M., and Miller, H. L., Cambridge University Press, Cambridge, UK, and New York, NY, USA, 2007.

Kaufman, Y. J.: Satellite Sensing of Aerosol Absorption, J. Geophys. Res., 92, 4307-4317, 1987.

Kaufman, Y. J., Tanré, D., Remer, L. A., Vermote, E. F., Chu, A., and Holben, B. N.: Operational remote sensing of tropospheric aerosol over land from EOS moderate resolution imaging spectroradiometer, J. Geophys. Res., 102, 17051-17067, 1997.

Kaufman, Y. J., Tanré, D., and Boucher, O.: A satellite view of aerosols in the climate system, Nature, 419, 215-223, doi:10.1038/nature01091, 2002.

Kokhanovsky, A. A. and Leeuw, G. D.: Satellite aerosol remote sensing over land, Environmental Sciences, Springer Praxis Books, 2009.

Kotchenova, S. Y., Vermote, E. F., Matarrese, R., and Klemm, F. J.: Validation of a vector version of the $6 \mathrm{~S}$ radiative transfer code for atmospheric correction of satellite data, Part I: Path radiance, Appl. Opt., 45, 6762-6774, doi:10.1364/AO.45.006762, 2006.

Kotchenova, S. Y., Vermote, E. F., Levy, R., and Lyapustin, A.: Radiative transfer codes for atmospheric correction and aerosol retrieval: intercomparison study, Appl. Opt., 47, 2215-2226, 2008.

Lohmann, U. and Feichter, J.: Global indirect aerosol effects: a review, Atmos. Chem. Phys., 5, 715-737, doi:10.5194/acp-5-7152005, 2005.

Popp, C., Hauser, A., Foppa, N., and Wunderle, S.: Remote sensing of aerosol optical depth over central Europe from MSG-SEVIRI data and accuracy assessment with ground-based AERONET measurements, J. Geophys. Res., 112, D24S11, doi:10.1029/2007JD008423, 2007.

Popp, C., Wang, P., Brunner, D., Stammes, P., Zhou, Y., and Grzegorski, M.: MERIS albedo climatology for FRESCO+ $\mathrm{O}_{2}$ A-band cloud retrieval, Atmos. Meas. Tech., 4, 463-483, doi:10.5194/amt-4-463-2011, 2011.

Ramanathan, V., Crutzen, P. J., Kiehl, J. T., and Rosenfeld, D.: Aerosols, climate, and the hydrological cycle, Science, 294, 2119-2124, doi:10.1126/science.1064034, 2001.

Riffler, M., Popp, C., Hauser, A., Fontana, F., and Wunderle, S.: Validation of a modified AVHRR aerosol optical depth retrieval algorithm over Central Europe, Atmos. Meas. Tech., 3, 12551270, doi:10.5194/amt-3-1255-2010, 2010.

Russell, P. B., Livingston, J. M., Pueschel, R. F., Bauman, J. J., Pollack, J. B., Brooks, S. L., Hamill, P., Thomason, L. W., Stowe, L. L., Deshler, T., Dutton, E. G., and Bergstrom, R. W.: Global to microscale evolution of the Pinatubo volcanic aerosol derived from diverse measurements and analyses, J. Geophys. Res., 101, 18745-18763, doi:10.1029/96JD01162, 1996.

Satheesh, S. K.: Letter to the Editor Aerosol radiative forcing over land: effect of surface and cloud reflection, Ann. Geophys., 20, 2105-2109, doi:10.5194/angeo-20-2105-2002, 2002. 
Sayer, A. M., Thomas, G. E., Grainger, R. G., Carboni, E., Poulson, C., and Siddans, R.: Use of MODIS-derived surface reflectance data in the ORAC-AATSR aerosol retrieval algorithm: Impact of differences between sensor spectral response functions, Remote Sens. Environ., 116, 177-188, doi:10.1016/j.rse.2011.02.029, 2012.

Seidel, F., Schläpfer, D., Nieke, J., and Itten, K.: Sensor Performance Requirements for the Retrieval of Atmospheric Aerosols by Airborne Optical Remote Sensing, Sensors, 8, 1901-1914, doi:10.3390/s8031901, 2008.

Seidel, F. C., Kokhanovsky, A. A., and Schaepman, M. E.: Fast retrieval of aerosol optical depth and its sensitivity to surface albedo using remote sensing data, Atmos. Res., in press, doi:10.1016/j.atmosres.2011.03.006, 2011.

Seinfeld, J. H. and Pandis, S. N.: Atmospheric Chemistry and Physics: From Air Pollution to Climate Change, John Wiley \& Sons, New York, USA, 1326 pp., 1998.

Smirnov, A., Holben, B. N., Giles, D. M., Slutsker, I., O’Neill, N. T., Eck, T. F., Macke, A., Croot, P., Courcoux, Y., Sakerin, S. M., Smyth, T. J., Zielinski, T., Zibordi, G., Goes, J. I., Harvey, M. J., Quinn, P. K., Nelson, N. B., Radionov, V. F., Duarte, C. M., Losno, R., Sciare, J., Voss, K. J., Kinne, S., Nalli, N. R., Joseph, E., Krishna Moorthy, K., Covert, D. S., Gulev, S. K., Milinevsky, G., Larouche, P., Belanger, S., Horne, E., Chin, M., Remer, L. A., Kahn, R. A., Reid, J. S., Schulz, M., Heald, C. L., Zhang, J., Lapina, K., Kleidman, R. G., Griesfeller, J., Gaitley, B. J., Tan, Q., and Diehl, T. L.: Maritime aerosol network as a component of AERONET - first results and comparison with global aerosol models and satellite retrievals, Atmos. Meas. Tech., 4, 583-597, doi:10.5194/amt-4-583-2011, 2011.
Sobolev, V. V.: Light scattering in planetary atmospheres (translated as Light scattering in planetary atmospheres, Pergamon Press, Oxford, 1975), Nauka, Moscow, 1972.

Teillet, P. M., Fedosejevs, G., Ahern, F. J., and Gauthier, R. P.: Sensitivity of surface reflectance retrieval to uncertainties in aerosol optical properties, Appl. Optics, 33, 3933-3940, 1994.

Vermote, E. F., Tanré, D., Deuzé, J. L., Herman, M., and Morcrette, J.-J.: Second Simulation of the Satellite Signal in the Solar Spectrum, 6S: an overview, IEEE T. Geosci. Remote, 35, 675-686, 1997.

Wells, K. C., Martins, J. V., Remer, L. A., Kreidenweis, S. M., and Stephens, G. L.: Critical reflectance derived from MODIS: Application for the retrieval of aerosol absorption over desert regions, J. Geophys. Res., 117, doi:10.1029/2011JD016891, 2012.

Zhang, J. and Reid, J. S.: A decadal regional and global trend analysis of the aerosol optical depth using a data-assimilation grade over-water MODIS and Level 2 MISR aerosol products, Atmos. Chem. Phys., 10, 10949-10963, doi:10.5194/acp-1010949-2010, 2010.

Zhu, L., Martins, J. V., and Remer, L. A.: Biomass burning aerosol absorption measurements with MODIS using the critical reflectance method, J. Geophys. Res., 116, D07202, doi:10.1029/2010JD015187, 2011. 